\title{
Poly(N-vinylcaprolactam) and Salicylic Acid Polymeric Prodrug Grafted onto Medical Silicone to Obtain a Novel Thermo- and pH-Responsive Drug Delivery System for Potential Medical Devices
}

\author{
José M. Cornejo-Bravo ${ }^{1}$ (), Kenia Palomino ${ }^{1}$, Giovanni Palomino-Vizcaino ${ }^{2}$, Oscar M. Pérez-Landeros ${ }^{3}$, \\ Mario Curiel-Alvarez ${ }^{3}$, Benjamín Valdez-Salas ${ }^{3}{ }^{\circledR}$, Emilio Bucio ${ }^{4}$ and Héctor Magaña ${ }^{1, *}$
}

1 Faculty of Chemical Sciences and Engineering, Autonomous University of Baja California, University Boulevard No. 14418, Otay Mesa, Tijuana 22390, Mexico; jmcornejo@uabc.edu.mx (J.M.C.-B.); kenia.palomino@uabc.edu.mx (K.P.)

2 Faculty of Health Sciences, Autonomous University of Baja California, University Boulevard No. 1000, Tijuana 22260, Mexico; gpalomino@uabc.edu.mx

3 Institute of Engineering, Autonomous University of Baja California, Benito Juárez Boulevard, Mexicali 21280, Mexico; oscar.manuel.perez.landeros@uabc.edu.mx (O.M.P.-L.); mcuriel@uabc.edu.mx (M.C.-A.); benval@uabc.edu.mx (B.V.-S.)

check for updates

Citation: Cornejo-Bravo, J.M.; Palomino, K.; Palomino-Vizcaino, G.; Pérez-Landeros, O.M.;

Curiel-Alvarez, M.; Valdez-Salas, B.; Bucio, E.; Magaña, H.

Poly(N-vinylcaprolactam) and Salicylic Acid Polymeric Prodrug Grafted onto Medical Silicone to Obtain a Novel Thermo- and pH-Responsive Drug Delivery System for Potential Medical Devices. Materials 2021, 14, 1065. https:// doi.org/10.3390/ma14051065

Academic Editor: John G. Hardy

Received: 30 January 2021

Accepted: 22 February 2021

Published: 25 February 2021

Publisher's Note: MDPI stays neutral with regard to jurisdictional claims in published maps and institutional affiliations.

Copyright: (c) 2021 by the authors. Licensee MDPI, Basel, Switzerland. This article is an open access article distributed under the terms and conditions of the Creative Commons Attribution (CC BY) license (https:/ / creativecommons.org/licenses/by/ $4.0 /)$.
4 Department of Radiation Chemistry and Radiochemistry, Institute of Nuclear Science, National Autonomous University of Mexico, Mexico City 04510, Mexico; ebucio@nucleares.unam.mx

* Correspondence: hector.magana@uabc.edu.mx

\begin{abstract}
New medical devices with anti-inflammatory properties are critical to prevent inflammatory processes and infections in medical/surgical procedures. In this work, we present a novel functionalization of silicone for medical use with a polymeric prodrug and a thermosensitive polymer, by graft polymerization (gamma rays), for the localized release of salicylic acid, an analgesic, and anti-inflammatory drug. Silicone rubber (SR) films were functionalized in two stages using graft polymerization from ionizing radiation $\left({ }^{60} \mathrm{Co}\right)$. The first stage was grafting poly $(N$-vinylcaprolactam) (PNVCL), a thermo-sensitive polymer, onto SR to obtain SR-g-PNVCL. In the second stage, poly(2methacryloyloxy-benzoic acid) (P2MBA), a polymeric prodrug, was grafted to obtain (SR-g-PNVCL)$g$-P2MBA. The degree of functionalization depended on the concentrations of monomers and the irradiation dose. The films were characterized by attenuated total reflectance Fourier-transform infrared spectroscopy (ATR-FTIR), scanning electron microscopy/energy-dispersive X-ray spectrometry (SEM-EDX), thermogravimetric analysis (TGA), and contact angle. An upper critical solution temperature (UCST) of the films was demonstrated by the swelling degree as a temperature function. (SR-g-PNVCL)- $g$-P2MBA films demonstrated hydrolysis-mediated drug release from the polymeric prodrug, $\mathrm{pH}$, and temperature sensitivity. GC-MS confirmed the presence of the drug (salicylic acid), after polymer hydrolysis. The concentration of the drug in the release media was quantified by HPLC. Cytocompatibility and thermo-/ $\mathrm{pH}$ sensitivity of functionalized medical silicone were demonstrated in cancer and non-cancer cells.
\end{abstract}

Keywords: medical devices; thermo-/pH sensitivity; graft copolymerization; polymeric prodrug; drug delivery; medical/surgical procedures

\section{Introduction}

Medical devices are crucial for the success of many medical/surgical procedures today [1]. They are classified based on the type of device, risk, and time of use [2,3]. Based on these characteristics, international health agencies (Food and Drug Administration, FDA) identify them as class I, II, and III devices [4]. Class III devices are high risk, and implantation into patients is long or prolonged [5]. Examples of these devices are coronary stents, pacemakers, and orthopedic and breast implants [6-8]. Many of these devices 
are made with different metallic alloys [9] or polymers [10]. Some of the most widely used polymers are polyvinyl chloride (PVC), polypropylene (PP), polyethylene (PE), and silicone rubber (SR) [11-13]. These polymeric materials have been widely used in medical device production due to their thermal and mechanical stability, biocompatibility, cheap production, and compatibility with many sterilization methods [14,15]. Similarly, the production of polymeric medical devices from additive manufacturing (3D printing) has increased due to the development of biocompatible scaffolds, precise device design, and minimal waste of materials during production [16-18].

SR is the most exploited material for breast implants due to its exceptional flexibility, extensibility, and biodurability [19], particularly those designed mainly for breast augmentation and reconstruction [20]. Some of the problems reported in patients with breast implants are infections, inflammation, hematomas, and seromas [21,22]. A proposal to solve these problems is to incorporate drugs or biomolecules into the device to achieve a therapeutic effect in the specific site or area. Usually, the medical materials are modified to gain drug-loading capacity [23].

Plasma and radiation are methods currently used to modify medical devices [24]. Particularly, the ionizing radiation from Cobalt- $60\left({ }^{60} \mathrm{Co}\right)$ serves to modify the surface and mass (bulk) of materials due to the high-frequency energy (gamma rays) to which a material is exposed, producing free radicals for grafting $[25,26]$. SR has been previously functionalized or copolymerized using direct [27], pre-irradiation [28], and pre-irradiation oxidative methods [29]. The direct method is based on a single step to irradiate the polymer matrix for modification in the presence of one or more monomers [30,31]. This process leads to the formation of free radicals or active sites in the polymer matrix due to high-energy irradiation that favors the initiation of a graft polymerization process [32].

Some of the methodological advantages are grafting several polymers in a single step, avoiding conventional catalysts or chemical initiators of a polymerization reaction, and obtaining a sterilized product [33]. Some of these functionalizations have included grafting stimulus-sensitive polymers such as poly( $N$-vinylcaprolactam) [34], poly(4-vinylpyridine) [35], poly(acrylic acid) [36], or poly(glycidyl methacrylate) [37].

Some of these polymers have a lower critical solution temperature (LCST), and others have an upper critical solution temperature (UCST) $[38,39]$. These properties are of great interest in the area of controlled drug release and biomaterials since it allows control in the loading or release of biomolecules under physiological conditions [40-42]. These grafted polymers manage to carry and deliver molecules with therapeutic activity, such as diclofenac, ibuprofen, nystatin, and lysozyme, due to noncovalent interactions (van der Waals, ionic, or hydrophobic interactions) [43,44].

Another route that has recently been explored is grafting medical devices using polymeric prodrugs, which subsequently can be degraded by hydrolysis, thus releasing the drug [45]. These polymeric prodrugs have advantages over previously described methods since the amount of drug present in the device is a function of the functionalization or graft percentage [46]. Merging more than one approach to functionalize medical devices generates "combined products," which have seen a significant boom in recent years [47,48]. This method offers numerous advantages, such as a site-specific release and preventive or prophylactic effects, and minimizes the first-pass effect of drugs [49-51]. The design and research of new "combined products" must focus on the devices being stable for biological applications and capable of responding to physiological stimuli such as $\mathrm{pH}$ and temperature.

In this context, the goal of this work was the modification of medical-grade silicone firstly with PNVCL, a temperature-sensitive polymer, and secondly with the polymeric prodrug P2MBA. The synthesized copolymer, (SR-g-PNVCL)-g-P2MBA, was characterized by ATR-FTIR, TGA, SEM-EDX, contact angle, swelling, and responsiveness to temperature. The degree of salicylic acid release by hydrolysis was evaluated at different $\mathrm{pH}$ values and temperatures by HPLC (quantitative-qualitative determination) and GC-MS (qualitative 
determination). Finally, the cytotoxicity of (SR-g-PNVCL)-g-P2MBA was evaluated in cancer and non-cancer cells.

\section{Materials and Methods}

\subsection{Materials}

SR of a $1 \mathrm{~mm}$ thickness was obtained from Goodfellow Cambridge Ltd (Huntingdon, UK). It was cut into $5 \times 2 \mathrm{~cm}^{2}$ films. The SR films were washed with ethyl alcohol to remove impurities for $2 \mathrm{~h}$. Subsequently, the films were dried under a vacuum at a temperature of $60{ }^{\circ} \mathrm{C}$ overnight. $\mathrm{N}$-vinylcaprolactam $98 \%$ was obtained from Sigma-Aldrich (St. Louis, $\mathrm{MO}$, USA) and purified by vacuum distillation. Salicylic acid, dimethylaminopyridine (DMAP), methacrylic anhydride, triethylamine, ethyl ether, dichloromethane $\left(\mathrm{CH}_{2} \mathrm{Cl}_{2}\right)$, p-dioxane, ethanol, magnesium sulfate, and petroleum ether (2MBA synthesis reagents) were acquired from Sigma-Aldrich. The reagents for HPLC (acetonitrile and methanol) were purchased from Sigma-Aldrich. A Hypersil GOLD C18 column $\left(250 \times 4.6 \mathrm{~mm}^{2}\right)$ was obtained from Thermo Scientific (Waltham, MA, USA). A 3-(4,5-dimethylthiazol-2-yl)-2,5diphenyltetrazolium bromide (MMT) kit was obtained from Roche (Basel, Switzerland).

Synthesis of 2MBA

The synthesis was achieved by placing DMAP $(0.49 \mathrm{~g})(4 \mathrm{mmol})$, salicylic acid $(6.91 \mathrm{~g})$ (50 mmol), $\mathrm{Et}_{3} \mathrm{~N}(8.42 \mathrm{~mL})$, and $\mathrm{CH}_{2} \mathrm{Cl}_{2}(20 \mathrm{~mL})$ in a round-bottomed flask $(100 \mathrm{~mL})$. Methacrylic anhydride $(7.50 \mathrm{~g})(50 \mathrm{mmol})$ was added little by little below $0{ }^{\circ} \mathrm{C}$ and with constant stirring conditions. The organic phase of the reaction was extracted with ethyl ether and recrystallized in vacuo. The precipitate (monomer or 2MBA) was purified in petroleum ether and p-dioxane and characterized by ${ }^{1}$ HNMR and ATR-FTIR [52].

\subsection{Grafting Process}

\subsubsection{Synthesis of SR-g-PNVCL (First Functionalization)}

SR films $\left(1 \times 2.5 \mathrm{~cm}^{2}\right)$ were functionalized with $N$-vinylcaprolactam by a direct graft method [53]. This process was carried out by irradiating the silicone films using a cobalt $\left({ }^{60} \mathrm{Co}\right)$ source, Gammabeam 651 PT, MDS Nordion, Ottawa, ON, Canada. Briefly, the films were placed in glass ampoules in a solution of monomer (NVCL) in toluene. The ampules were degassed, closed, and irradiated to initiate a graft polymerization process. The films were removed from the ampules and washed with ethanol and water to remove monomer or homopolymer impurities from the reaction. SR-g-PNVCL films were dried under a vacuum, and the percentage of grafting was calculated.

\subsubsection{Synthesis of (SR-g-PNVCL)-g-P2MBA (Second Functionalization)}

Similarly, the SR-g-PNVCL films were placed in glass ampoules in a concentrated monomer solution (1 M/toluene) and exposed to conditions of a direct method using irradiation doses of 5, 10, 20,30, 40, and $50 \mathrm{kGy}$. These experiments were essential to determine if the graft grade was a function of dose. Furthermore, the monomer concentration effect was evaluated, using concentrations of $0.0125,0.025,0.05,0.10,0.25,0.50$, and $0.75 \mathrm{M}$ (in these experiments, a dose of $5 \mathrm{kGy}$ was established). For both experiments, at the end of the procedure, the ampules were opened, and the films were removed, washed with ethanol, and dried under vacuum. For the first and second grafting processes, the graft was calculated using Equation (1) [43]:

$$
\text { Grafting }(\%)=\frac{W_{F}-W_{I}}{W_{I}} \times 100
$$

where $\mathrm{w}_{\mathrm{F}}$ is the weight of the grafted film and $\mathrm{w}_{\mathrm{I}}$ is the initial weight. 


\subsection{Characterization of (SR-g-PNVCL)-g-(P2MBA) Films}

\subsubsection{ATR-FTIR Analysis}

The SR, SR- $g$-PNVCL, and (SR-g-PNVCL)- $g$-P2MBA films were characterized using ATR-FTIR, at a range of $4000-650 \mathrm{~cm}^{-1}$ with 16 scans using a Perkin-Elmer Spectrum 100 spectrometer (Perkin Elmer Cetus Instrument, Norwalk, CT, USA).

\subsubsection{TGA Analysis}

The modified and unmodified films (15-20 mg) were characterized by thermogravimetric analysis using TGA Q50 equipment (TA Instruments, New Castle, DE, USA). These experiments were achieved under inert atmosphere. The heat rate was $10^{\circ} \mathrm{C} / \mathrm{min}$ from 25 to $800{ }^{\circ} \mathrm{C}$.

\subsubsection{SEM-EDX Analysis}

The SR, SR-g-PNVCL, and (SR-g-PNVCL)-g-P2MBA films of $0.5 \times 1 \mathrm{~cm}^{2}$ were analyzed by SEM-EDX. The film surfaces and cross-sections were observed to identify possible functionalization sites due to the graft polymerizations. A JSM-6010LA (JEOL, Tokyo, Japan) instrument was used under low-vacuum conditions (30 Pa) and an acceleration voltage of $15 \mathrm{kV}$.

\subsubsection{Contact Angle, Swelling, and Temperature-Responsive Analysis}

The unmodified and modified films' contact angle was evaluated by placing water droplets on different spots of the surface area. A Kruss DSA 100 device (Matthews, NC, USA) was used. Limit swelling tests were performed by placing films in $20 \mathrm{~mL}$ of water at room temperature. The films were weighed before placing them in water and subsequently weighed at 10, 20, 40,50, and $60 \mathrm{~min}$. The swelling percentage was determined as follows [43]:

$$
\text { Swelling }(\%)=\frac{\mathrm{W}_{2}-\mathrm{W}_{1}}{\mathrm{~W}_{1}} \times 100
$$

where $\mathrm{w}_{2}$ and $\mathrm{w}_{1}$ represent the weights of the swollen film and dried film, respectively.

The thermal sensitivity of the (SR- $g$-PNVCL)- $g$-P2MBA films was determined by weighing dry films and subsequently swelling them in $20 \mathrm{~mL}$ of distilled water for $24 \mathrm{~h}$ at different temperatures $\left(28-34^{\circ} \mathrm{C}\right)$. The weight difference was found based on Equation (2).

\subsection{Drug Release and Characterization Analysis (HPLC and GC-MS)}

SR-g-PNVCL and (SR-g-PNVCL)-g-P2MBA) films (7.6\% and $33.5 \%)\left(0.5 \times 1 \mathrm{~cm}^{2}\right.$; 20-25 mg) were placed in phosphate-buffered saline (PBS) at pH 5.5 and $7.4(5 \mathrm{~mL})$ at $50 \mathrm{RPM}$ and $37^{\circ} \mathrm{C}$ (physiological pH levels and temperature) in a Mini Shaker VWR (West Chester, PA, USA). Aliquots were taken at different sampling times, and subsequently, the samples were quantified by HPLC using Ultimate 3000 Thermo scientific equipment (Waltham, MA, USA). The separation mechanism was by reverse-phase RP-HPLC, using a Hypersil COLD Column (Thermo Scientific) $\left(250 \times 4.6 \mathrm{~mm}^{2}\right)$, octadecyl silica type (ODS or C18). A sample injection volume of $10 \mu \mathrm{L}$ was used, with a column temperature of $40^{\circ} \mathrm{C}$, using a mobile phase of PBS and acetonitrile (70:30), with a flow rate of $1 \mathrm{~mL} / \mathrm{min}$. Finally, a photodiode array detector was used. The concentration was determined by performing calibration lines of salicylic acid of a known concentration at a wavelength of $235 \mathrm{~nm}$. The amount of salicylic acid present or grafted on the film (SR-g-PNVCL)-g-P2MBA was determined by Equation (3) [45]:

Salicylic acid $(\mathrm{mg} / \mathrm{g})=\frac{\text { Grafting }(\%)}{(100+\text { Grafting }(\%)) \times\left(\mathrm{MW}_{2 \mathrm{MBA}}\right)} \times\left(\mathrm{MW}_{\text {Salicylic acid }}\right) \times 1000$

The hydrolysis-release process was evaluated by the first- and zero-order models. Statgraphics Centurion 18 software (version 18.1.13 2020, Statgraphics Technologies Inc., The Plains, VA, USA) [54] was used for this modeling. The salicylic acid HPLC retention time of the problem samples was compared with a standard. The salicylic acid molecular 
ion was also identified from the release media employing gas chromatography-mass spectrometry (GC-MS). The release medium was exposed to ethyl ether to carry out extraction of the organic phase. The ethyl ether was evaporated, and the precipitate was resuspended in methanol. This solution was injected into a Thermo Scientific TRACE 1310 gas chromatograph model. This gas chromatograph was coupled to a mass spectrograph (single quadrupole), namely, the Thermo Scientific ISQ LT model. Helium was used as a mobile phase at a flow rate of $1 \mathrm{~mL} / \mathrm{min}$. A temperature ramp of $40^{\circ} \mathrm{C} / \mathrm{min}$ was carried out until reaching a temperature of $280^{\circ} \mathrm{C}$.

\subsection{Cytocompatibility Analysis}

Murine embryonic fibroblast cell line BALB/3T3 (ATCC CCL-163, Manassas, VA, USA) and human cervical cancer cell line HeLa (ATCC CCL-2, Manassas, VA, USA) were used to determine the viability percentage after exposure to the modified materials as we previously reported. Briefly, the assays were carried out in 96-well plates seeded with 3000 cells per well in Dulbecco's modified Eagle's medium (DMEM) medium with FBS (Fetal bovine serum, $10 \% v / v)$, penicillin-streptomycin $(1 \% w / v)$, and gentamicin $(10 \mu \mathrm{g} / \mathrm{mL})$ for $12 \mathrm{~h}$ in culture standard conditions. The SR, SR-g-PNVCL, (SR-g-PNVCL)-g-P2MBA 1\% (graft percent), (SR-g-PNVCL)-g-P2MBA 7\%, and SR-g-PNVCL)- $g$-P2MBA $17 \%\left(0.25 \times 0.20 \mathrm{~cm}^{2}\right)$ films were submersed in the cell media and incubated in a humidified atmosphere of $5 \%$ $\mathrm{CO}_{2}$ at $37^{\circ} \mathrm{C}$ for 24 or $48 \mathrm{~h}$. On the contrary, for the functional characterization after $12 \mathrm{~h}$ of incubation, the SR, SR-g-PNVCL, SR-g-(PNVCL/P2MBA) 1\%, SR-g-(PNVCL/P2MBA 7\%, and SR-g-(PNVCL/P2MBA $17 \%\left(0.25 \times 0.2 \mathrm{~cm}^{2}\right)$ films were placed in direct contact with the cell media and maintained in standard conditions of $5 \% \mathrm{CO}_{2}$ at $37{ }^{\circ} \mathrm{C}$ and adequate humidity for $12 \mathrm{~h}$. After this time, the incubator temperature was set to $30^{\circ} \mathrm{C}$ for a soft temperature change overnight, and the cell viability was analyzed at $48 \mathrm{~h}$. The films were removed, and an MTT kit was used to quantify the cell viability. Cells without films were used as a negative, and all experiments were performed in triplicate. Lastly, the absorbances were measured by spectrophotometry at $620 \mathrm{~nm}$ (Multiskan FC, Thermo Scientific). The statistical data evaluation was done by one-way ANOVA using GraphPad Prism 7 (San Diego, CA, USA). The cytocompatibility was determined as follows Equation (4) [46]:

$$
\text { Cytocompatibility }(\%)=\frac{\mathrm{Abs}_{\text {Sample }}}{\mathrm{Abs}_{\text {Control }}} \cdot 100
$$

\section{Results}

\subsection{Grafting Process}

\subsubsection{Synthesis of SR-g-PNVCL}

The functionalization of PNVCL in the silicone films (Figure 1) was carried out successfully according to the previously reported method [53]. The films were irradiated at $50 \mathrm{kGy}$ and in 50\% monomer (NVCL) toluene solutions.

Toluene played a critical role in this phase, as it helped the swelling of the films, thus favoring the migration of the monomeric solution throughout the silicone polymeric matrix $[55,56]$. The obtained results were consistent with the literature, in which a graft percentage between 37 and $38 \%$ was obtained [53]. In this way, the first phase of modifying the silicone polymer matrix (SR-g-PNVCL) was performed. 


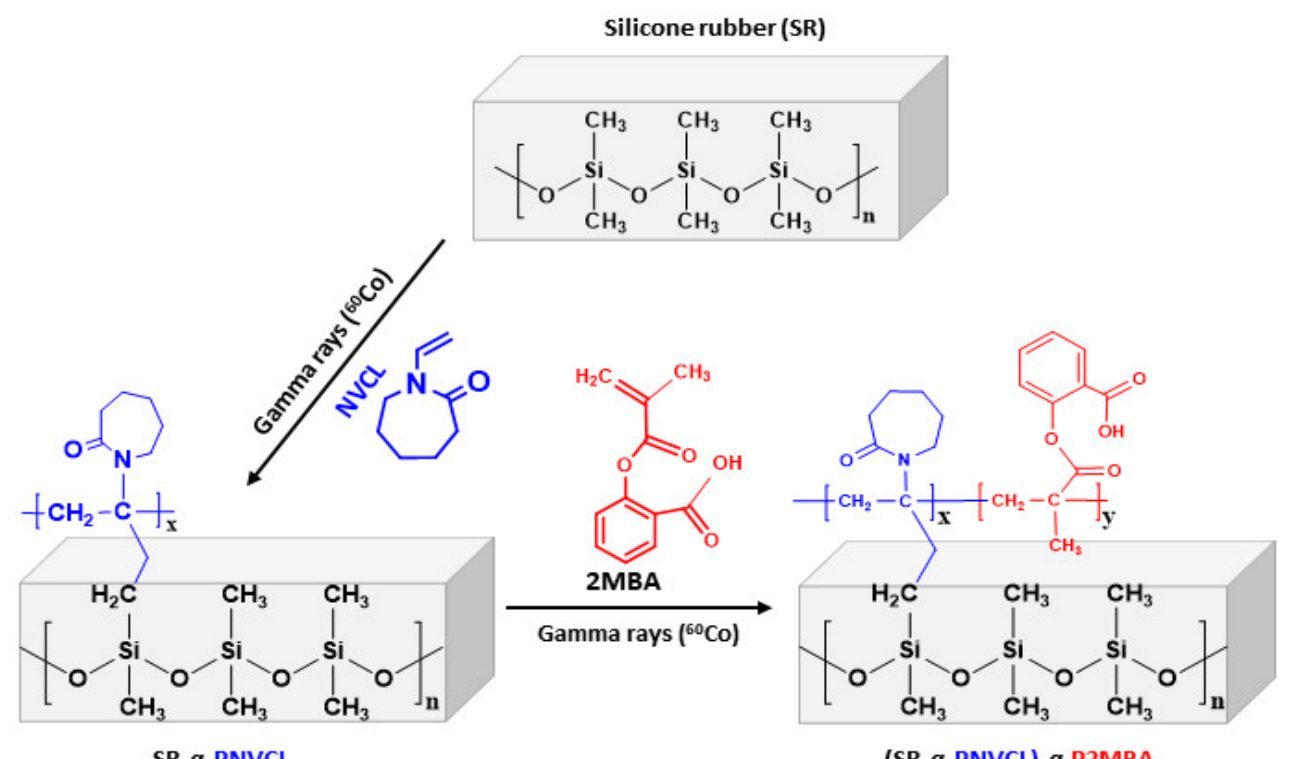

Figure 1. Functionalization of silicone rubber (SR) with NVCL and 2MBA by gamma radiation method.

\subsubsection{Synthesis of (SR-g-PNVCL)-g-P2MBA}

Once the SR-g-PNVCL films were synthesized, experiments were carried out to as-sess the factors that could influence the degree of grafting of the proposed new monomer (2MBA) (Figure 1). A monomer concentration $(1 \mathrm{M})$ was established, and the irradiation dose was varied between 5 and $50 \mathrm{kGy}$ (Figure 2A). An increase in the graft grade (64 to $108.6 \%$ ) was indeed found with the proposed doses because the higher the energy of radi-ation to which the polymeric matrix (SR-g-PNVCL) is subjected, the more radical sites there are to promote a graft polymerization process [57]. Once it was shown that the dose effect was essential to moderate the degree of grafting, the concentration of the monomer in the reactions was varied. An amount of $5 \mathrm{kGy}$ and monomer concentrations between 0.0125 and $0.75 \mathrm{M}$ were established. Graft percentages between 0.816 and $52.01 \%$ were observed (Figure 2B), thus demonstrating that the higher the monomer's concentration in the solution, the greater the graft capacity [56]. With the method above, it was possible to establish the monomeric concentration essential to control the films' degree of functionalization.
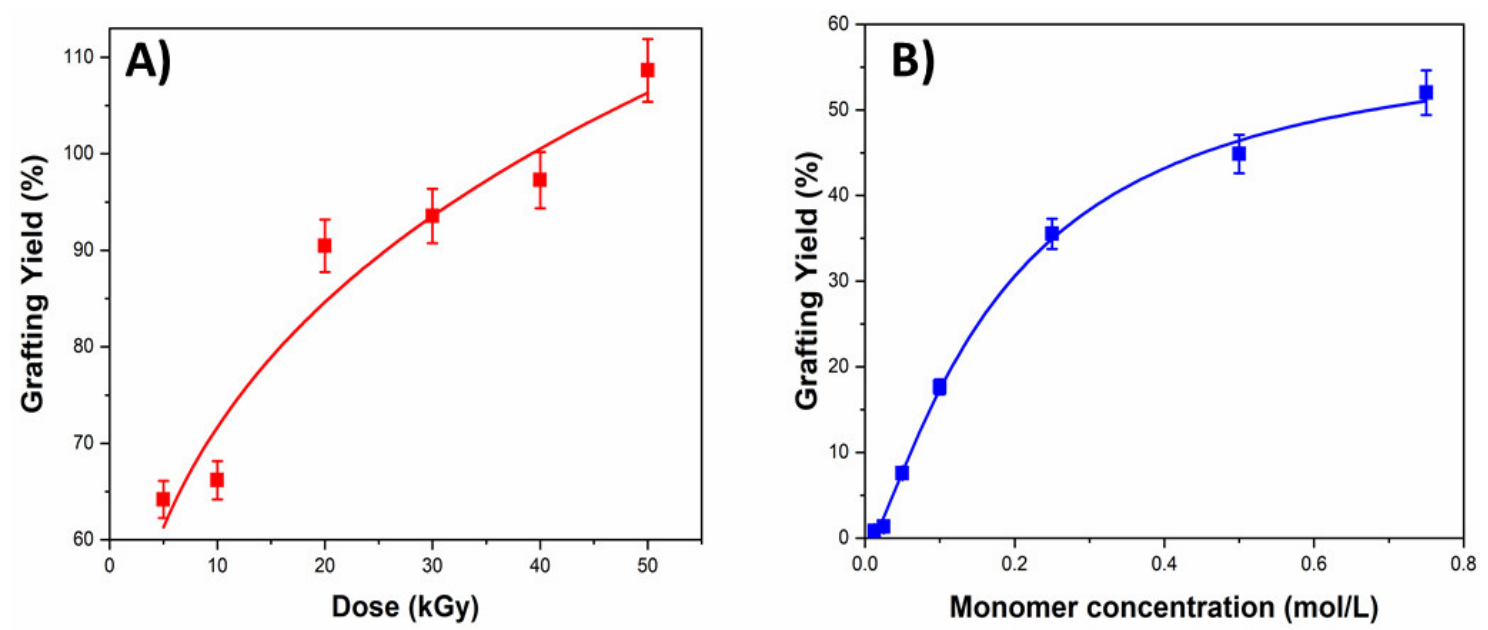

Figure 2. Grafting percentages of $2 \mathrm{MBA}$ onto SR-g-PNVCL films as a function of (A) monomer concentration and (B) absorbed dose. 


\subsection{Characterization of (SR-g-PNVCL)-g-P2MBA Films}

\subsubsection{ATR-FTIR Analysis}

Figure 3 shows the spectra's chronology until obtaining the target copolymerized system (SR-g-PNVCL)-g-P2MBA. First (Figure 3a), with SR as the base matrix for the synthesis, characteristic bonds were observed, such as at $2964 \mathrm{~cm}^{-1}$, corresponding to the $\mathrm{C}-\mathrm{H} \mathrm{sp}{ }^{3}$ stretching mode; at $1257 \mathrm{~cm}^{-1}$, a band corresponding to the $\mathrm{Si}-\mathrm{CH}_{3}$ stretch; at $997 \mathrm{~cm}^{-1}$, the stretch of $\mathrm{Si}-\mathrm{O}-\mathrm{Si}$; at $820 \mathrm{~cm}^{-1}$, a signal corresponding to the $\mathrm{Si}-\left(\mathrm{CH}_{3}\right)_{2}$ bending mode [58]. The characterization of the PNVCL (homopolymer), was carried out, this being the polymer to be grafted onto the silicone. PNVCL presented characteristic bands (Figure $3 \mathrm{~b}$ ), such as at $2923 \mathrm{~cm}^{-1}$, corresponding to the $\mathrm{C}-\mathrm{H}$ sp $\mathrm{sp}^{3}$ stretching mode, at $1625 \mathrm{~cm}^{-1}$, an intense band corresponding to amide carbonyl (N-C=O), and at $1479 \mathrm{~cm}^{-1}$, a band corresponding to the $\mathrm{C}-\mathrm{N}$ stretch [59]. In Figure 3c, the evidence of the first functionalization (SR-g-PNVCL) can be observed. At $1635 \mathrm{~cm}^{-1}$, the stretching of the amide carbonyl $(\mathrm{N}-\mathrm{C}=\mathrm{O})$, corresponding to PNVCL, as well as the $\mathrm{C}-\mathrm{N}$ stretch band at $1477 \mathrm{~cm}^{-1}$, can be observed. Bands at 1265, 998, and $821 \mathrm{~cm}^{-1}$, corresponding to stretching of $\mathrm{Si}-\mathrm{CH}_{3}, \mathrm{Si}-\mathrm{O}-\mathrm{Si}$, and $\mathrm{Si}-\left(\mathrm{CH}_{3}\right)_{2}$, can be observed, all the previous signals proper to silicone, ensuring the first functionalization [53]. In Figure $3 d$, bands of the P2MBA (homopolymer), the second polymer proposed for functionalization, can be observed. At $2945 \mathrm{~cm}^{-1}$, a signal corresponding to $\mathrm{C}-\mathrm{H} \mathrm{sp}{ }^{3}$ is present, and between 3100 and $2800 \mathrm{~cm}^{-1}$, there is a broad band attributed to the $\mathrm{O}-\mathrm{H}$ stretching of the carboxylic acid. At 1724 and $1710 \mathrm{~cm}^{-1}$, bands corresponding to the $\mathrm{C}=\mathrm{O}$ stretch of the ester groups, carbonyls and carbolic acid, can be observed. At $1600 \mathrm{~cm}^{-1}$, bands correspond to the $\mathrm{C}=\mathrm{C}$ stretch of the aromatic region of P2MBA, and at $960 \mathrm{~cm}^{-1}$, there is an intense band corresponding to the $\mathrm{C}-\mathrm{H}$ bending (out of plane) aromatic di-substitution in the ortho-position [52].

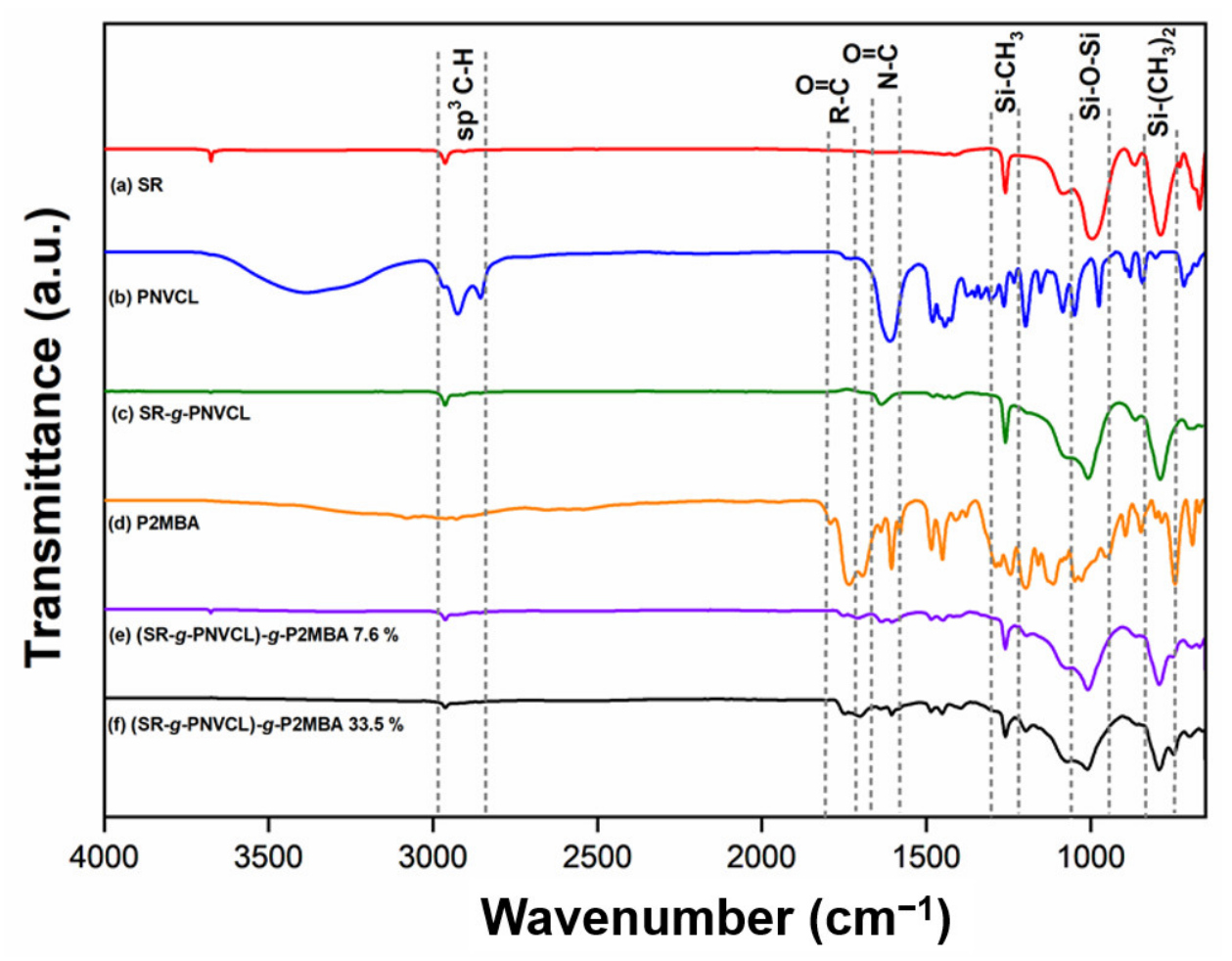

Figure 3. ATR-FTIR spectra of SR (a), PNVCL (b), SR-g-PNVCL (c), P2MBA (d), (SR-g-PNVCL)- $g$-P2MBA 7.6\% (e), and (SR-g-PNVCL)-g-P2MBA 33.5\% (f).

Finally, in Figure 3e,f, bands of $\mathrm{Si}-\mathrm{CH}_{3}, \mathrm{Si}-\mathrm{O}-\mathrm{Si}$, and $\mathrm{Si}-\left(\mathrm{CH}_{3}\right)_{2}$ at 1265,998 , and $821 \mathrm{~cm}^{-1}$ can be seen, corresponding to SR. At $1725 \mathrm{~cm}^{-1}$, carbonyl bands $(\mathrm{C}=\mathrm{O})$ can be observed, attributed to the presence of P2MBA, thus demonstrating that the second proposed functionalization of (SR-g-PNVCL)- $g$-P2MBA was achieved. 


\subsubsection{TGA Analysis}

Thermogravimetric analyses (Figure 4) were carried out to appreciate the different end stabilities of the polymers involved and the changes that may arise in the proposed synthesized system of (SR-g-PNVCL)-g-P2MBA. In the first phase of copolymerization, SR and PNVCL were involved. Figure 4 shows how SR presents a single thermal degradation at $517{ }^{\circ} \mathrm{C}$ [53]. On the contrary, PNVCL presents a thermal degradation at $434{ }^{\circ} \mathrm{C}$ [59]. Consequently, in the first functionalization carried out (SR-g-PNVCL), two degradations can be observed, the first between 385 and $452{ }^{\circ} \mathrm{C}$ (corresponding to PNVCL) and the second from 452 to $600{ }^{\circ} \mathrm{C}$ (corresponding to SR), demonstrating a correct functionalization of SR-g-PNVCL, as well as a correlation with previously described infrared experiments that demonstrate the graft [44]. The second stage of functionalization was carried out with P2MBA, as shown in Figure 4. Two thermal decompositions can be observed, the first at $221{ }^{\circ} \mathrm{C}$ and the second at $393{ }^{\circ} \mathrm{C}$ [45]. In the (SR-g-PNVCL)- $g$-P2MBA samples with a graft grade of 7.6 and $33.5 \%$, different intervals of thermal decompositions can be observed. In the sample with a graft of $7.6 \%$, a first decomposition phase occurred between 220 and $350{ }^{\circ} \mathrm{C}$, attributed to P2MBA and PNVCL. Compared to the film with the highest graft $(33.5 \%)$, this first phase has a decrease between 220 and $320^{\circ} \mathrm{C}$; this is because the higher the graft percentage, the more significant the similarity to the homopolymer.

The second degradation phase for the graft of $7.6 \%$ occurred between 400 and $450{ }^{\circ} \mathrm{C}$, and the third between 450 and $600{ }^{\circ} \mathrm{C}$, attributed to SR. The results of these experiments demonstrate that grafting was achieved in two stages, as we were able to observe previously in infrared tests and as, depending on the percentage of P2MBA graft, we could increase or decrease the stability of the proposed system. These results indicate the potential of this final system (SR-g-PNVCL)-g-P2MBA, with grafts in the order of 7.6 to $33.5 \%$ for biomedical applications, as they would not suffer any degradation or modification since the temperature body temperature is around $37^{\circ} \mathrm{C}[60]$.

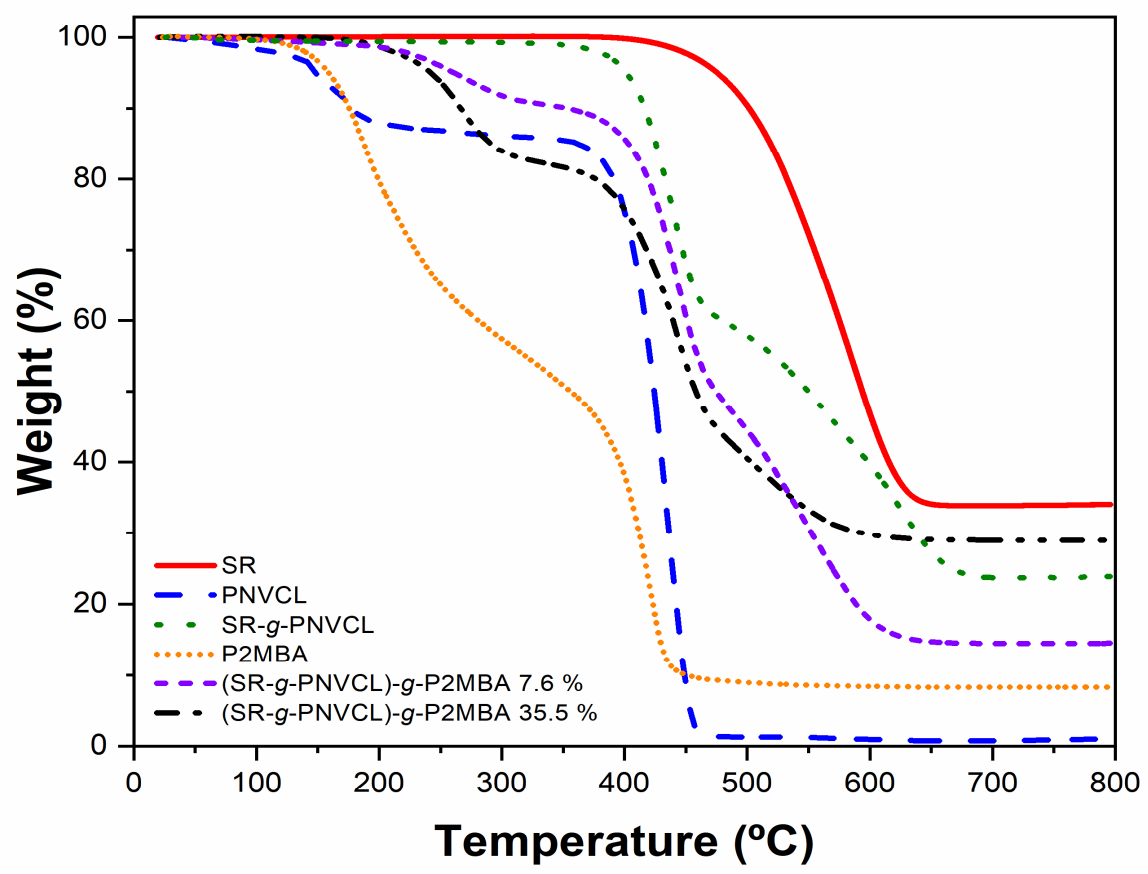

Figure 4. TGA thermograms of SR, PNVCL, SR-g-PNVCL, P2MBA, (SR-g-PNVCL)-g-P2MBA 7.6\%, and (SR-g-PNVCL)-g-P2MBA 33.5\%.

\subsubsection{SEM-EDX Analysis}

After spectrophotometric (Figure 3) and thermogravimetric (Figure 4) characterizations that demonstrated the grafting of the final synthesized system, characterization was carried out by scanning electron microscopy (Figure 5) in order to be able to identify 
changes in the topography of the films and to determine if the graft of PNVCL and P2MBA was made on the surface of the films or in bulk. Figure 5A shows the surface of SR, in which irregular and traditional topography can be observed, as previously reported [28,61]. EDX analysis showed carbon, oxygen, silicon, and magnesium atoms [62]. Magnesium and aluminum metals were previously reported in the literature and play a vital role in synthesizing silicone for the vulcanization process $[63,64]$. The surface of SR-g-PNVCL (Figure 5B) shows morphology similar to that of SR, but through EDX, there was an increase in the percentage of carbon mass $(10 \%)$ due to the PNVCL graft. In Figure 5C, the film's surface can be observed, referring to the second grafting stage to obtain (SR-g-PNVCL)$g$-P2MBA. The second functionalization showed a change in the film's topography, with a smooth surface compared with the previous ones. This effect was previously observed, and it demonstrates that the P2MBA graft was on the film's surface [46]. The EDX analysis (Figure $5 \mathrm{~A}-\mathrm{C}$ ) showed an increase of $24 \%$ in the mass percentage of carbon regarding SR and of an additional $14 \%$ for SR-g-PNVCL, attributed to the grafted P2MBA.
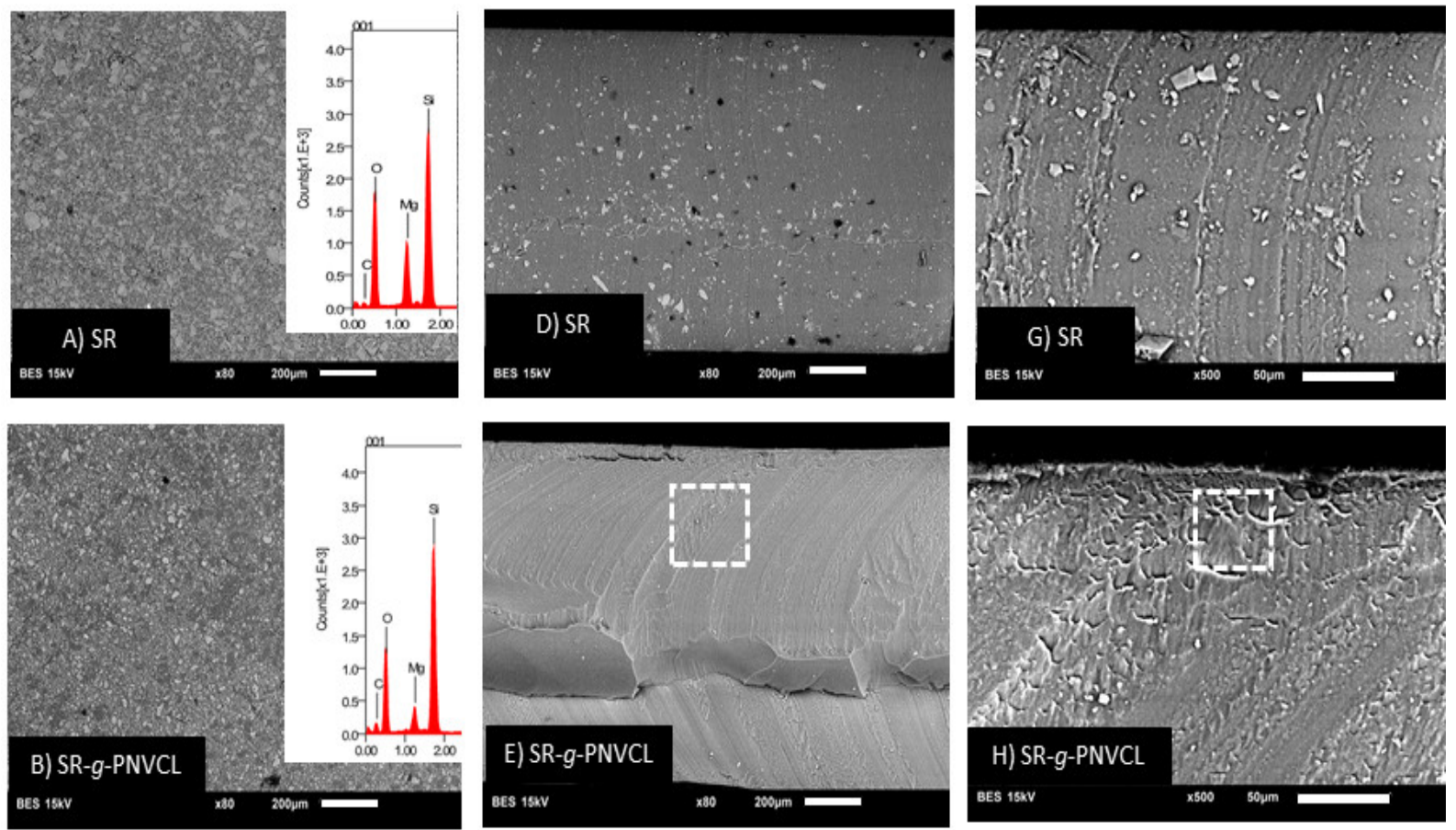

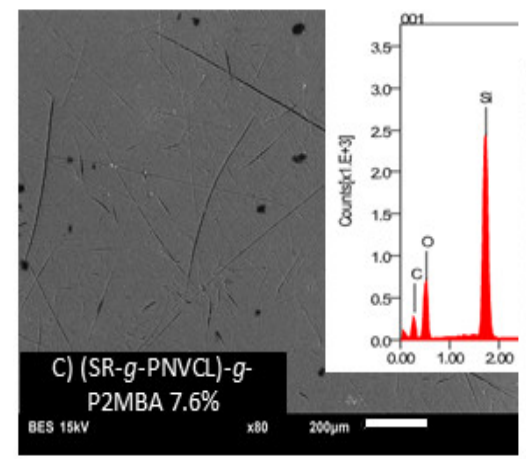

Surface

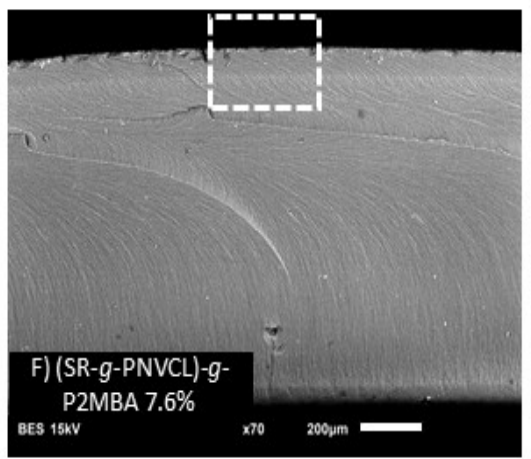

Cross-sections

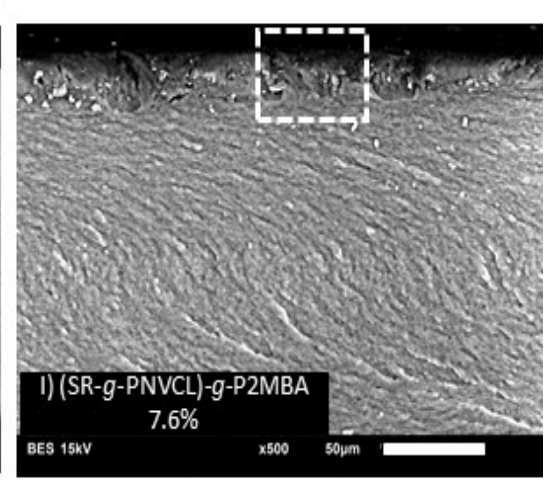

Cross-sections

Figure 5. SEM images of the surface of (A) SR, (B) SR-g-PNVCL, (C) (SR-g-PNVCL)-g-P2MBA 7.6\%, and the cross-section of SR, SR-g-PNVCL, and (SR-g-PNVCL)-g-P2MBA 7.6\% (D-F) $(200 \mu \mathrm{m}) ;(\mathrm{G}-\mathrm{I})(50 \mu \mathrm{m}))$. Dashed line square indicates grafting areas.

Later, the morphology of the films was observed in the cut section. In Figure 5D, which corresponds to SR, an irregular morphology with traditional dark deposits can be 
observed [65]. When the PNVCL graft was performed, a total change in the transversal section's morphology occurred, as seen in the Figure 5E. These changes have been previously reported and demonstrate how the PNVCL graft was carried out in the same way in bulk [66]. Carrying out the graft polymerization process in toluene produces swelling of the silicone films and favors bulk grafting [55]. In Figure 5F, a regular morphology can be observed compared with the previous ones, as well as the formation of a new layer in the upper part. The layer can be appreciated with a more significant enlargement of the cross-sectional area (Figure 5I). This effect is characteristic and was previously observed in film grafts [45]. It is important to differentiate this from Figure $5 \mathrm{H}$, referring to SR-g-PNVCL, where the layer can also be observed in the upper part but is less than in (SR-g-PNVCL)-g-P2MBA. SR-g-PNVCL cross-section films can be seen, characteristic of the fact that the graft was also being carried out in bulk. In the silicone cross-section (Figure 5G), the graft's layer and different morphologies from the two functionalizations cannot be observed.

\subsubsection{Contact Angle, Swelling, and Temperature Responsiveness Analysis}

Contact angle analysis was carried out to determine the hydrophobic or hydrophilic nature of the material. Thus, the behavior of the films could be predicted when in contact with physiological aqueous media. Figure 6A shows how SR presented a contact angle of $99^{\circ}$, demonstrating a hydrophobic material attributed to methyl groups distributed throughout the polymer chain $[67,68]$. Once the first functionalization (SR-g-PNVCL) was carried out, the films presented a contact angle of $90^{\circ}$. This decrease is due to the polar groups of PNVCL, which favor hydrophilic interaction with aqueous media [44]. The P2MBA graft in the order of $0.816-33.5 \%$ showed a decrease in the contact angle of $86.7^{\circ}-78.8^{\circ}$. This decrease in contact angle is attributed to the polar groups (carboxylic acids) present in P2MBA [69]. At high graft percentages (64.1\% and 93.8\%), an increase in the contact angle $\left(83.1^{\circ}\right.$ and $\left.93.6^{\circ}\right)$ was observed; this is attributed to the fact that the greater the graft, the greater the intramolecular interactions of P2MBA, causing a hydrophobic effect [70]. A swelling test was also performed (Figure 6B). The swelling of the films was observed over time, with silicone, due to its previously described hydrophobic characteristics, exhibiting zero swelling up to $240 \mathrm{~min}$. Films with the first copolymerization (SR-g-PNVCL) showed a constant increase in the percentage of swelling over time, with a swelling of up to $21 \%$. This swelling was due to an increase in the film's hydrophilicity, attributed to the grafted polar groups of PNVCL. The (SR-g-PNVCL)-g-P2MBA films, with 7.6 and $33.5 \%$ grafts, showed swelling of 3.20 and $1.26 \%$, respectively, demonstrating that the higher the P2MBA graft, the lower the swelling. These results favorably indicate that the material, when used in biomedical applications, would not undergo swelling processes at high grafting percentages, which could result in deformation or damage to other materials in a medical device [46]. The swelling degree as a function of temperature was also investigated. This experiment aimed to detect the swollen/unswollen transition temperature of the films (Figure 7).

PNVCL is a well-known thermoresponsive material with an LCST close to the body temperature [71]. Interestingly, PNVCL grafted on SR presents a UCST instead of an LCST [45]. The transition was maintained for copolymeric grafts of PNVCL and ionizable monomers [32,72]. It is noteworthy that only a few polymers present a UCST, which is attributed to the weakening of the associative interactions among polymer chains when the temperature is above a certain threshold, which favors the contact of individualized chains with the aqueous medium [73,74]. In our work, the (SR-g-PNVCL)-g-P2MBA films with 7.6 and $33.5 \%$ grafts showed a UCST at $30.5^{\circ} \mathrm{C}$ (Figure 7). This phenomenon is relevant in the hydrolysis of the drug, as discussed below. 

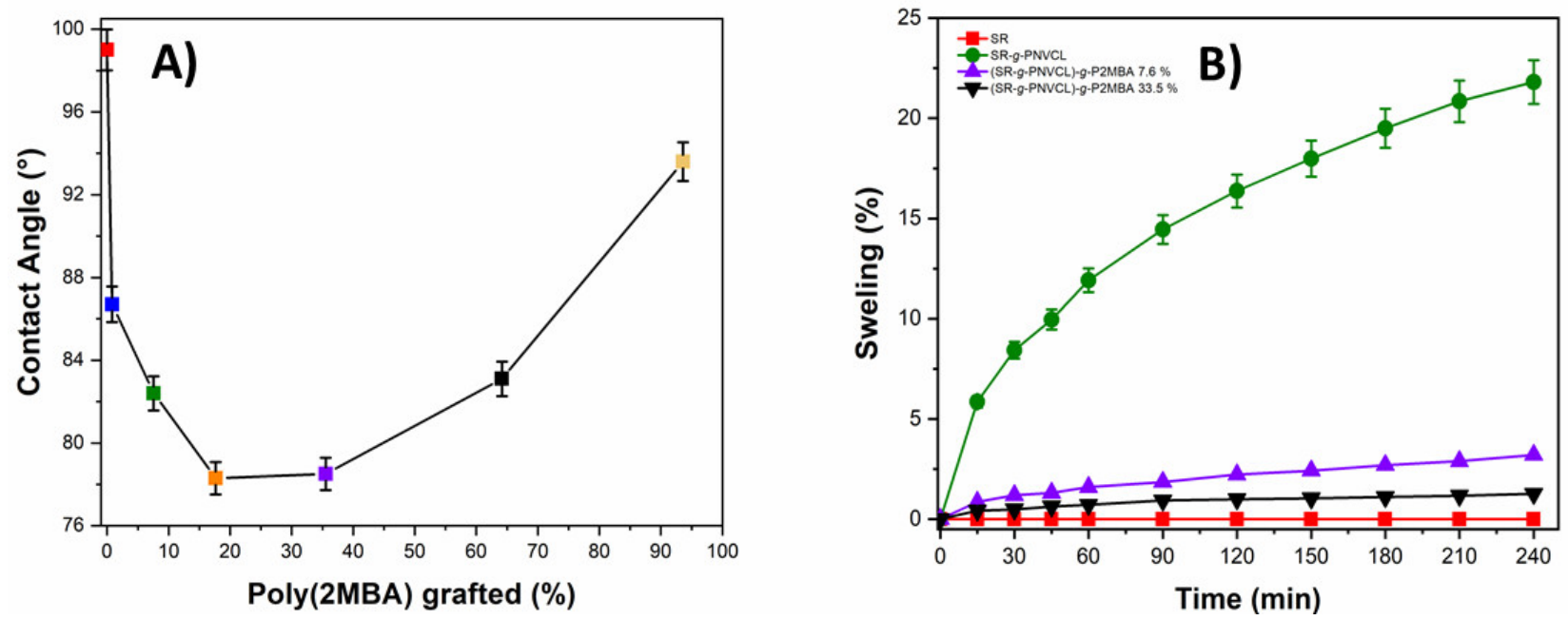

Figure 6. (A) Water contact and (B) swelling profile of SR and (SR-g-PNVCL)- $g$-P2MBA films.

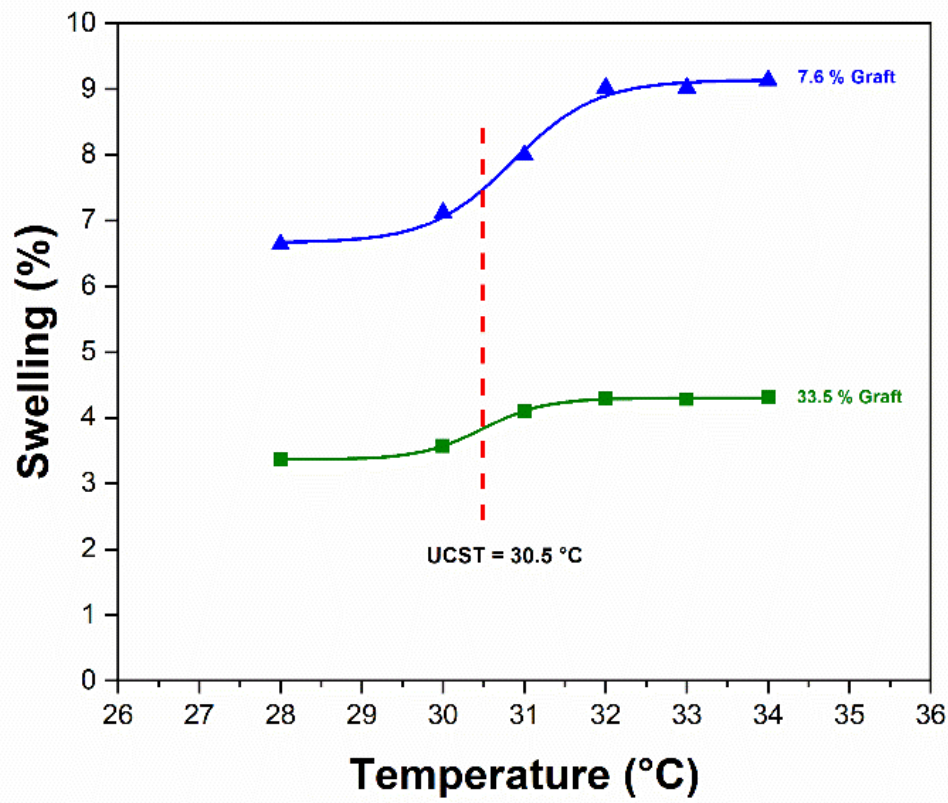

Figure 7. Temperature response by swelling of (SR- $g$-PNVCL)- $g$-P2MBA films.

\subsection{Drug Release and Characterization Analysis (HPLC and GC-MS)}

In the HPLC chromatogram in Figure 8, the retention time at 3.421 min corresponds to the peak of the salicylic acid (standard solution) and at $3.411 \mathrm{~min}$, the peak of the salicylic acid release samples occurred at $\mathrm{pH}=7.4$, which confirms that salicylic acid is present in the investigated sample. Additionally, a release sample (previously extracted with organic solvent) was injected into the GC-MS. The MS spectrum presents the molecular ion of salicylic acid (138.17 m/z) (Figure 8). For instance, the presence of the salicylic acid released from the (SR-g-PNVCL)- $g$-P2MBA films was confirmed by two methods. 

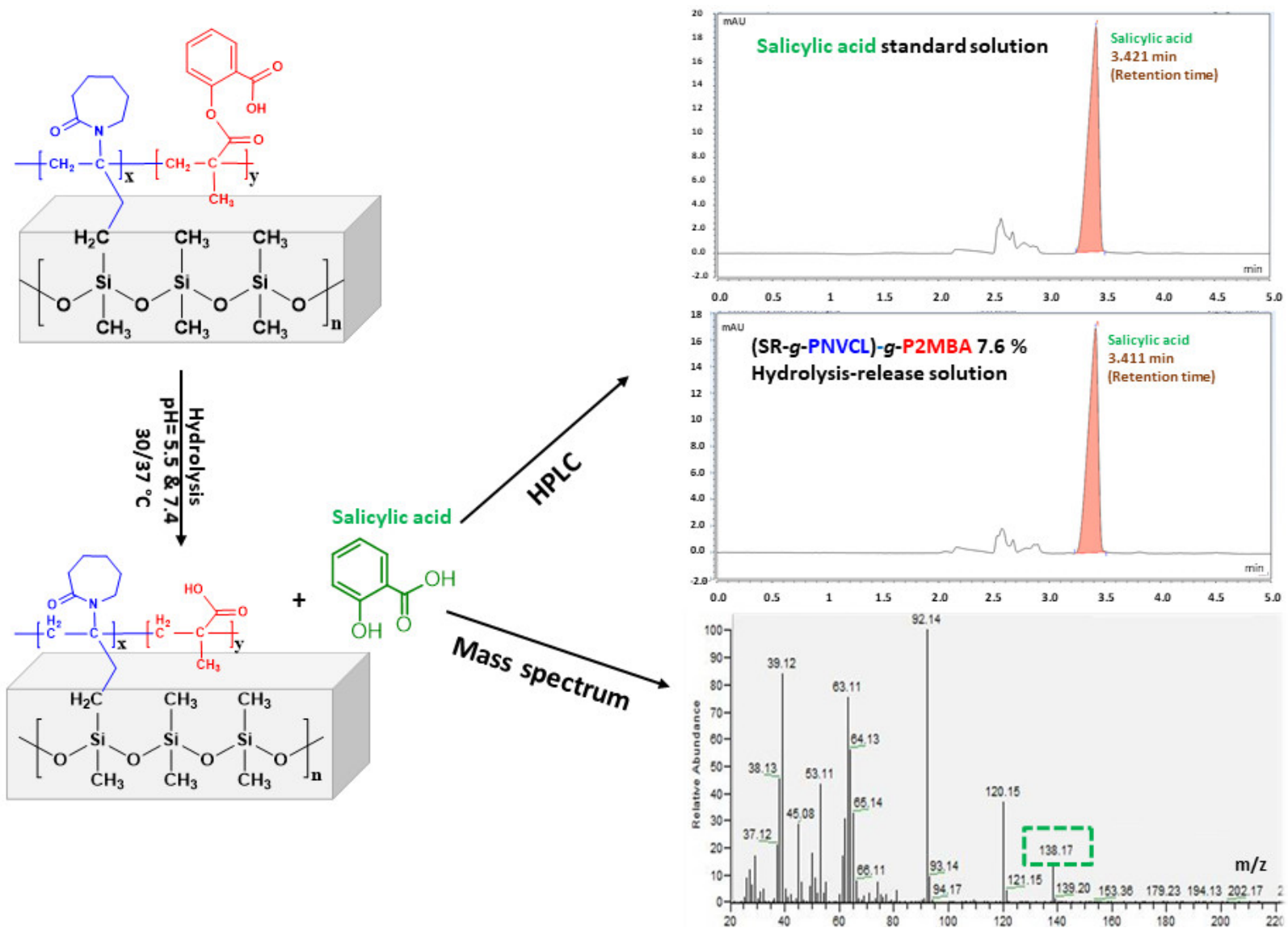

Figure 8. Hydrolysis-release of salicylic acid from (SR-g-PNVCL)- $g$-P2MBA films, HPLC quantification, and molecular ion detection.

Figure 9 shows the kinetics of salicylic acid hydrolysis from the modified (SR-gPNVCL)-g-P2MBA films. The rate of hydrolysis was evaluated at $30^{\circ} \mathrm{C}$ (below the UCST) and $37^{\circ} \mathrm{C}$ (above the UCST), and pH 5.5 and 7.4 (physiological pH) [75]. In Figure 9A, films with a graft percentage of 7.6 and $33.5 \%$ at $\mathrm{pH} 5.5$ show a sustained release for $120 \mathrm{~h}$. Films with a $7.6 \%$ graft at $37^{\circ} \mathrm{C}$ show $74.5 \mathrm{mg} / \mathrm{g}$ of drug released compared with $55 \mathrm{mg} / \mathrm{g}$ released at $30^{\circ} \mathrm{C}(120 \mathrm{~h})$. Faster hydrolysis at $37^{\circ} \mathrm{C}$ (above the UCST) is due to the highest swelling of the films, favoring the interaction with the aqueous medium with the grafted polymeric chains of P2MBA. The films with $33.5 \%$ graft showed less drug release than the low grafts $(7.6 \%)$, due to the lower swelling of the films. Additionally, grafting of $33.5 \%$ at $37^{\circ} \mathrm{C}$ showed a faster release $(48.3 \mathrm{mg} / \mathrm{g})$ than at $30^{\circ} \mathrm{C}(18.7 \mathrm{mg} / \mathrm{g})$, at $120 \mathrm{~h}$ due to the differences in swelling at the temperatures studied. At pH 7.4 (Figure 9B), films with a graft of $7.6 \%$ at $30{ }^{\circ} \mathrm{C}$ presented a lower release $(85.1 \mathrm{mg} / \mathrm{g})$ than at $37^{\circ} \mathrm{C}(135.8 \mathrm{mg} / \mathrm{g})$ at $120 \mathrm{~h}$, because of the differences in swelling at both temperatures. It is important to compare how these same films released a larger amount of the drug at $\mathrm{pH} 7.4$ than at $\mathrm{pH} 5.5$ since hydrolysis of polyester bonds (P2MBA) is favored by basic catalysis and the higher solubility of salicylic acid at higher $\mathrm{pH}$ [76]. It is observed that at $48 \mathrm{~h}, 7.6 \%$ graft releases more salicylic acid than $33.5 \%$ due to the higher swelling shown (Figure 7). However, at $72 \mathrm{~h}$ (pH 7.4), the process is reversed; films with 33.5\% graft showed a release of $210 \mathrm{mg} / \mathrm{g}$ of salicylic acid at $37^{\circ} \mathrm{C}$, and $35.9 \mathrm{mg} / \mathrm{g}$ at $30^{\circ} \mathrm{C}$, at $120 \mathrm{~h}$. This result is due to the higher content of prodrug in the higher grafted films. 

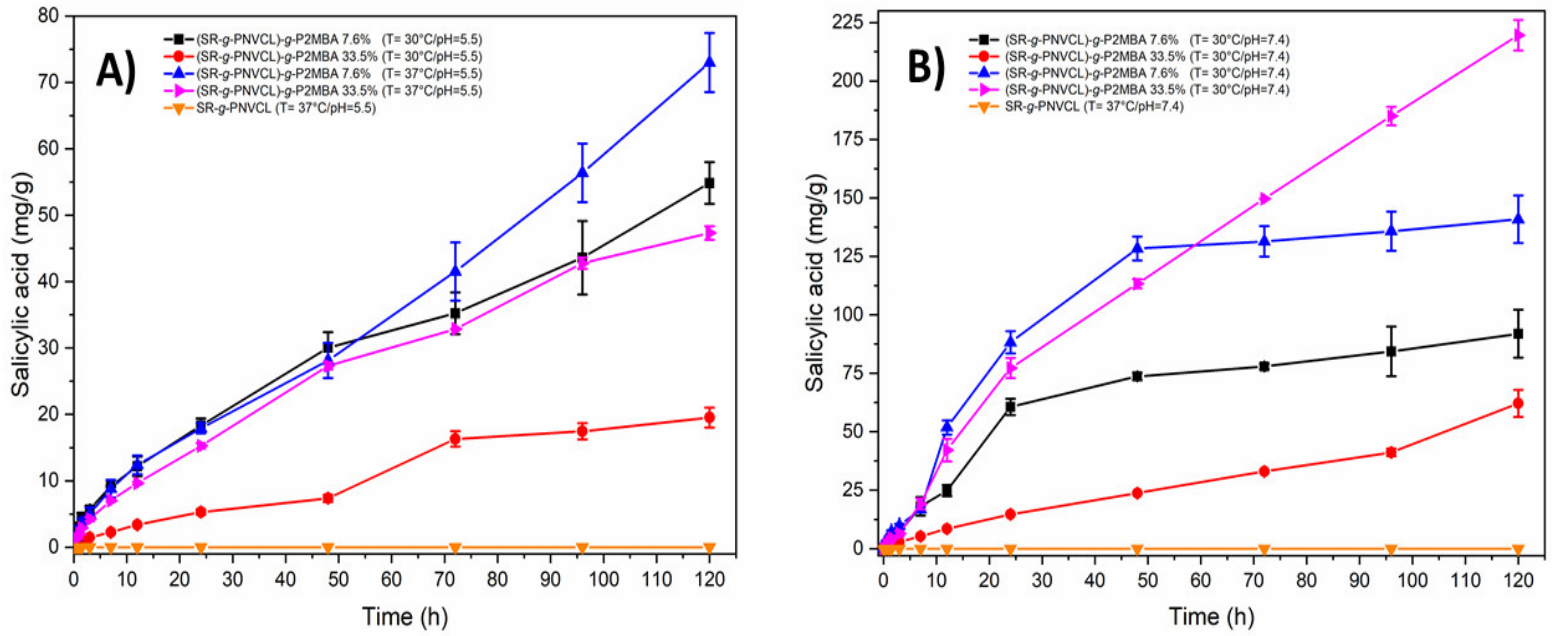

Figure 9. Salicylic acid release profile from (SR-g-PNVCL)- $g$-P2MBA films at (A) $\mathrm{pH}=5.5$ and (B) $\mathrm{pH}=7.4$.

It can be observed how a combination of films with high grafts, alkaline media (pH 7.4), and a temperature higher than $30.5^{\circ} \mathrm{C}$ (UCST of the films) favors greater hydrolysis of salicylic acid grafted in the synthesized matrixes. With this, it was demonstrated that the synthesized materials are responsive to $\mathrm{pH}$ and temperature. Table 1 shows the kinetic models followed by the hydrolysis-release data. The results fit well to either zero-order or first-order kinetics. Table 1 shows the kinetic models followed by the hydrolysis-release data. The results fit well to either zero-order or first-order kinetics. Table 1 also presents the rate constants values. We observe a higher zero-order rate constant for the higher conditions (loading, $\mathrm{pH}$, and temperature) studied. Three of the studies with lower loading follow first-order kinetics. Again, the higher constant value is observed for the higher $\mathrm{pH}$ and temperature studied.

Table 1. Salicylic acid release kinetics data for (SR-g-PNVCL)- $g$-P2MBA films.

\begin{tabular}{cccccc}
\hline P2MBA Graft (\%) & Release Medium pH & Temperature $\left({ }^{\circ} \mathbf{C}\right)$ & Model & Rate Constants & $\mathbf{R}^{\mathbf{2}}$ \\
\hline 7.6 & 5.5 & 30 & First order & $0.015 \mathrm{~h}^{-1}$ & 0.991 \\
33.5 & 5.5 & 30 & Zero order & $0.170 \mathrm{mg} / \mathrm{g} \mathrm{h}$ & 0.9696 \\
7.6 & 5.5 & 37 & Zero order & $0.569 \mathrm{mg} / \mathrm{g} \mathrm{h}$ & 0.994 \\
33.5 & 5.5 & 37 & Zero order & $0.401 \mathrm{mg} / \mathrm{g} \mathrm{h}$ & 0.978 \\
7.6 & 7.4 & 30 & First order & $0.026 \mathrm{~h}^{-1}$ & 0.966 \\
33.5 & 7.4 & 30 & Zero order & $0.469 \mathrm{mg} / \mathrm{g} \mathrm{h}$ & 0.985 \\
7.6 & 7.4 & 37 & First order & $0.037 \mathrm{~h}^{-1}$ & 0.967 \\
33.5 & 7.4 & 37 & Zero order & $1.867 \mathrm{mg} / \mathrm{g} \mathrm{h}$ & 0.9792 \\
\hline
\end{tabular}

\subsection{Cytocompatibility Analysis}

Cell viability was assessed in small volumes of growing medium in direct contact with BALB/3T3 (mouse) and HeLa (human) cell lines in small volumes of growing medium (Figure 10).

Cell viability was observed to be unaffected for very low-graft films (1\%) in both cell lines, while good cell viability (>90\%) was observed at $24 \mathrm{~h}$ for HeLa (Figure 10B) with 7 and $17 \%$ graft films, but not for BALB/3T3 cells (80\%), presumably because a tumorigenic phenotypic cell such as HeLa can handle the microenvironmental acidity, a hallmark of cancer cells [77]. As previously reported, a high salicylic acid concentration decreases cell viability in a lymphocyte culture, in a $\mathrm{pH}$-dependent way [78]. In the current study, a significant reduction in the cell viability $(60 \%)$ was observed at $48 \mathrm{~h}$ for HeLa (Figure 10A) with $17 \%$ graft films, and for BALB/3T3 (Figure 10A) with 7 and $17 \%$ graft films, at $37{ }^{\circ} \mathrm{C}$ (Figure 10B). However, at $30^{\circ} \mathrm{C}$, no significant cell viability reduction was observed at any contact time for the 2MBA grafted materials. In this condition, the salicylic acid release is 
expected to be low because of the polymer's reduced swelling. The results show that the polymer prodrug is responsive to temperature in a functional assay.
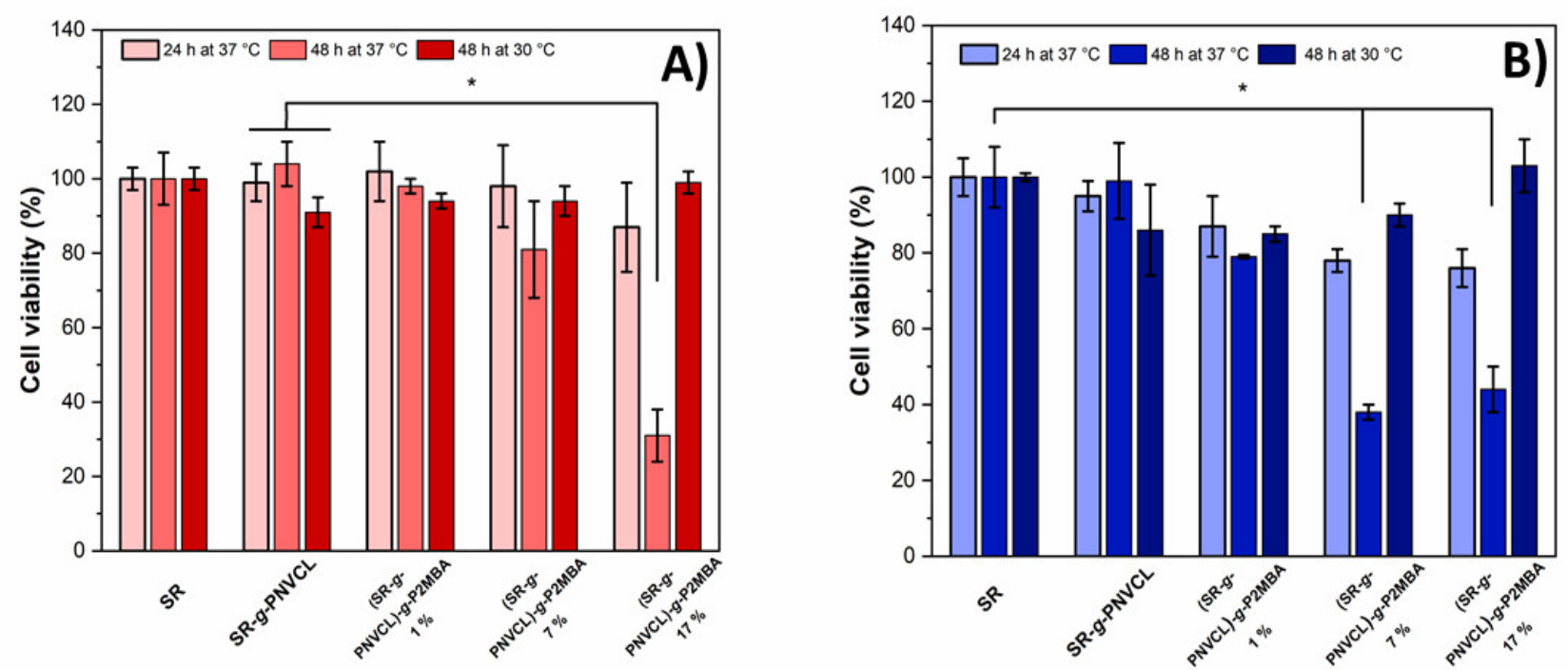

Figure 10. Viability of (A) BALB/3T3 and (B) HeLa cells in contact with SR, SR-g-PNVCL, and (SR- $g$-PNVCL)- $g$-P2MBA films. Asterisks indicate statistical significance between samples $(p<0.05)$.

\section{Conclusions}

Modification of SR through two-stage graft polymerization was carried out, demonstrating that the concentration of a monomer (NVCL and 2MBA) and the radiation dose are critical factors to control the percentage of functionalization grafting. The characterizations by infrared spectroscopy and thermogravimetric analysis demonstrated the adequate incorporation of PNVCL in the first stage and P2MBA in the second stage. The scanning electron microscopy showed us how the graft was performed on the surface and bulk silicone. The swelling tests showed that the (SR-g-PNVCL)-g-P2MBA system had a UCST at $30.5^{\circ} \mathrm{C}$. Modified SR exposed to higher temperatures (above the UCST) demonstrated faster hydrolysis-release of salicylic acid, due to the higher swelling above the UCST, which favors contact of the material with aqueous media, triggering hydrolysis. These results are relevant since the faster release of the drug at higher temperatures proves the concept that materials with a UCST around body temperature can be used to control the release of anti-inflammatory drugs in response to fever caused by infections or in response to induced local heating [79]. The studies at different $\mathrm{pH}$ values showed that basic catalysis and higher solubility of salicylic acid at higher $\mathrm{pH}$ favors a more significant hydrolysis-drug release process. The cytocompatibility studies demonstrated how cancer and non-cancer cell viability is dependent on the environmental temperature. $\mathrm{pH}$-/temperature-sensitive $\mathrm{SR}$ as a site-specific sustained-release polymeric prodrug system in medical devices is a promising strategy for prophylactic treatment in medical/surgical procedures.

Author Contributions: Conceptualization, E.B. and O.M.P.-L.; methodology, K.P.; software, G.P.V.; validation, G.P.-V. and M.C.-A.; formal analysis, J.M.C.-B.; investigation, K.P.; resources, E.B.; writing—original draft preparation, E.B., J.M.C.-B., and H.M.; writing-review and editing, H.M. and J.M.C.-B.; visualization, O.M.P.-L. and B.V.-S.; supervision, M.C.-A. and B.V.-S. All authors have read and agreed to the published version of the manuscript.

Funding: This work was funded by SEP's Grant Program to support New Full Time Professors PRODEP 2018 (UABC-PTC-735), New Full-Time Professors PRODEP 2020 (UABC-PTC-852 and UABC-PTC-853), Third Special Internal Call for Support to Research Projects (UABC-3902), the 20th Internal Call for Research Project's Funding UABC (3900), Dirección General de Asuntos del Personal Académico, Universidad Nacional Autónoma de México under Grant IN202320 and Call for basic 
scientific research CONACYT 2017-2018 del “Fondo Sectorial de Investigación para la educación CB2017-2018" (Grant A1-S-29789).

Institutional Review Board Statement: Not applicable.

Informed Consent Statement: Not applicable.

Data Availability Statement: Data sharing is not applicable to this article.

Acknowledgments: The authors acknowledge the technical support of the staff at ICN-UNAM (Benjamín Leal, Martín Cruz, and Enrique Palacios).

Conflicts of Interest: The authors declare no conflict of interest.

\section{References}

1. Song, W.; Li, J.; Li, H.; Ming, X. Human factors risk assessment: An integrated method for improving safety in clinical use of medical devices. Appl. Soft Comput. 2020, 86, 105918. [CrossRef]

2. Grennan, M.; Town, R.J. Regulating Innovation with Uncertain Quality: Information, Risk, and Access in Medical Devices. Am. Econ. Rev. 2020, 110, 120-161. [CrossRef]

3. Aronson, J.K.; Ferner, R.E. Clarification of Terminology in Drug Safety. Drug Saf. 2005, 28, 851-870. [CrossRef] [PubMed]

4. Aronson, J.K.; Heneghan, C.; Ferner, R.E. Medical Devices: Definition, Classification, and Regulatory Implications. Drug Saf. 2019, 43, 83-93. [CrossRef]

5. Vajapey, S.P.; Li, M. Medical Device Recalls in Orthopedics: Recent Trends and Areas for Improvement. J. Arthroplast. 2020, 35, 2259-2266. [CrossRef] [PubMed]

6. McKittrick, C.M.; Cardona, M.J.; Black, R.A.; McCormick, C. Development of a Bioactive Polymeric Drug Eluting Coronary Stent Coating Using Electrospraying. Ann. Biomed. Eng. 2020, 48, 271-281. [CrossRef] [PubMed]

7. Li, B.; Moriarty, T.F.; Webster, T.; Xing, M. Racing for the Surface: Antimicrobial and Interface Tissue Engineering; Springer: Morgantown, WV, USA, 2020; ISBN 9783030344719.

8. Benito-Ruiz, J.; Redondo, A. Breast Augmentation Surgery: How Do We Do It? Results of a Joint Survey from European Association of Societies of Aesthetic Plastic Surgery. Aesthetic Plast. Surg. 2020, 44, 1957-1964. [CrossRef] [PubMed]

9. Geyao, L.; Yang, D.; Wanglin, C.; Chengyong, W. Development and application of physical vapor deposited coatings for medical devices: A review. Procedia CIRP 2020, 89, 250-262. [CrossRef]

10. Almouse, R.; Wen, X.; Na, S.; Anderson, G.; Xie, D. Polyvinylchloride surface with enhanced cell/bacterial adhesion-resistant and antibacterial functions. J. Biomater. Appl. 2019, 33, 1415-1426. [CrossRef]

11. Zanocco, M.; Marin, E.; Boschetto, F.; Adachi, T.; Yamamoto, T.; Kanamura, N.; Zhu, W.; McEntire, B.J.; Bal, B.S.; Ashida, R.; et al. Surface Functionalization of Polyethylene by Silicon Nitride Laser Cladding. Appl. Sci. 2020, 10, 2612. [CrossRef]

12. Asadinezhad, A.; Lehocký, M.; Sáha, P.; Mozetič, M. Recent Progress in Surface Modification of Polyvinyl Chloride. Materials 2012, 5, 2937-2959. [CrossRef]

13. Slettengren, M.; Mohanty, S.; Kamolvit, W.; Van Der Linden, J.; Brauner, A. Making medical devices safer: Impact of plastic and silicone oil on microbial biofilm formation. J. Hosp. Infect. 2020, 106, 155-162. [CrossRef]

14. Bernard, M.; Jubeli, E.; Pungente, M.D.; Yagoubi, N. Biocompatibility of polymer-based biomaterials and medical devicesRegulations, in vitroscreening and risk-management. Biomater. Sci. 2018, 6, 2025-2053. [CrossRef]

15. Teo, A.J.; Mishra, A.; Park, I.; Kim, Y.-J.; Park, W.-T.; Yoon, Y.-J. Polymeric Biomaterials for Medical Implants and Devices. ACS Biomater. Sci. Eng. 2016, 2, 454-472. [CrossRef]

16. Bracaglia, L.G.; Smith, B.T.; Watson, E.; Arumugasaamy, N.; Mikos, A.G.; Fisher, J.P. 3D printing for the design and fabrication of polymer-based gradient scaffolds. Acta Biomater. 2017, 56, 3-13. [CrossRef]

17. Arrabito, G.; Ferrara, V.; Bonasera, A.; Pignataro, B. Artificial Biosystems by Printing Biology. Small 2020, 16, e1907691. [CrossRef] [PubMed]

18. Mu, X.; Fitzpatrick, V.; Kaplan, D.L. From Silk Spinning to 3D Printing: Polymer Manufacturing using Directed Hierarchical Molecular Assembly. Adv. Health Mater. 2020, 9, e1901552. [CrossRef] [PubMed]

19. Daniels, A.U. Silicone breast implant materials. Swiss Med. Wkly. 2012, 142, 1-12. [CrossRef] [PubMed]

20. Kang, S.H.; Bengtson, B.P.; Heo, C.Y. Various Properties of Silicone Breast Implant Surfaces and Multimodal Techniques for the Functional Surface Modification. Clin. Plast. Surg. 2021, 48, 87-99. [CrossRef]

21. Mujagic, E.; Zeindler, J.; Coslovsky, M.; Hoffmann, H.; Soysal, S.D.; Mechera, R.; Von Strauss, M.; Delko, T.; Saxer, F.; Glaab, R.; et al. The association of surgical drains with surgical site infections-A prospective observational study. Am. J. Surg. 2019, 217, 17-23. [CrossRef]

22. Hallab, N.J.; Samelko, L.; Hammond, D. The Inflammatory Effects of Breast Implant Particulate Shedding: Comparison With Orthopedic Implants. Aesthetic Surg. J. 2019, 39, S36-S48. [CrossRef] [PubMed]

23. Johnson, A.R.; Forster, S.P.; White, D.; Terife, G.; Lowinger, M.; Teller, R.S.; Barrett, S.E. Drug eluting implants in pharmaceutical development and clinical practice. Expert Opin. Drug Deliv. 2021, 1-17. [CrossRef] 
24. Ratner, B.D.; Hoffman, A.S.; McArthur, S.L. Physicochemical Surface Modification of Materials Used in Medicine, 4th ed.; Elsevier: Pittsburgh, PA, USA, 2020; ISBN 978-0-12-816137-1.

25. Pino-Ramos, V.H.; Meléndez-Ortiz, H.I.; Ramos-Ballesteros, A.; Bucio, E. Radiation Grafting of Biopolymers and Synthetic Polymers; Elsevier Inc.: Amsterdam, The Netherlands, 2018; ISBN 9780128104620.

26. Vázquez, E.; Muro, C.; Illescas, J.; Burillo, G.; Hernández, O.; Rivera, E. Obtainment and Characterization of Hydrophilic Polysulfone Membranes by N-Vinylimidazole Grafting Induced by Gamma Irradiation. Polymer 2020, 12, 1284. [CrossRef]

27. Meléndez-Ortiz, H.I.; Alvarez-Lorenzo, C.; Burillo, G.; Magariños, B.; Concheiro, A.; Bucio, E. Radiation-grafting of Nvinylimidazole onto silicone rubber for antimicrobial properties. Radiat. Phys. Chem. 2015, 110, 59-66. [CrossRef]

28. Cabana, S.; Lecona-Vargas, C.S.; Meléndez-Ortiz, H.I.; Contreras-García, A.; Barbosa, S.; Taboada, P.; Magariños, B.; Bucio, E.; Concheiro, A.; Alvarez-Lorenzo, C. Silicone rubber films functionalized with poly(acrylic acid) nanobrushes for immobilization of gold nanoparticles and photothermal therapy. J. Drug Deliv. Sci. Technol. 2017, 42, 245-254. [CrossRef]

29. Fuke, C.A.; Mahanwar, P.A.; Chowdhury, S.R. Modified ethylene-propylene-diene elastomer (EPDM)-contained silicone rubber/ethylene-propylene-diene elastomer (EPDM) blends: Effect of composition and electron beam crosslinking on mechanical, heat shrinkability, electrical, and morphological properties. J. Appl. Polym. Sci. 2019, 136, 1-8. [CrossRef]

30. Chapiro, A. Radiation induced grafting. Radiat. Phys. Chem. 1977, 9, 55-67. [CrossRef]

31. Pérez-Calixto, M.; González-Pérez, G.; Dionisio, N.; Bucio, E.; Burillo, G.; García-Uriostegui, L. Surface functionalization of polypropylene and polyethylene films with allylamine by $\gamma$ radiation. MRS Commun. 2019, 9, 264-269. [CrossRef]

32. Pino-Ramos, V.H.; Ramos-Ballesteros, A.; López-Saucedo, F.; López-Barriguete, J.E.; Varca, G.H.C.; Bucio, E. Radiation Grafting for the Functionalization and Development of Smart Polymeric Materials. Top. Curr. Chem. 2016, 374, 63. [CrossRef]

33. Ramos-Ballesteros, A.; Pino-Ramos, V.H.; López-Saucedo, F.; Flores-Rojas, G.G.; Bucio, E. $\gamma$-Rays and Ions Irradiation. Surf. Modif. Polym. 2019, 185-209. [CrossRef]

34. Flores-Rojas, G.G.; López-Saucedo, F.; Vázquez, E.; Hernández-Mecinas, E.; Huerta, L.; Cedillo, G.; Concheiro, A.; AlvarezLorenzo, C.; Bucio, E. Synthesis of polyamide-6@cellulose microfilms grafted with N-vinylcaprolactam using gamma-rays and loading of antimicrobial drugs. Cellulose 2020, 27, 2785-2801. [CrossRef]

35. Kavaklı, P.A.; Kavaklı, C.; Seko, N.; Tamada, M.; Güven, O. Radiation induced emulsion graft polymerization of 4-vinylpyridine onto PE/PP nonwoven fabric for As(V) adsorption. Radiat. Phys. Chem. 2016, 127, 13-20. [CrossRef]

36. Hidzir, N.M.; Kępa, K.; Hill, D.J.T.; Jorgensen, L.; Grøndahl, L. Protein adsorption to poly(tetrafluoroethylene) membranes modified with grafted poly(acrylic acid) chains. Biointerphases 2020, 15, 031011. [CrossRef] [PubMed]

37. Zuñiga-Zamorano, I.; Meléndez-Ortiz, H.I.; Costoya, A.; Alvarez-Lorenzo, C.; Concheiro, A.; Bucio, E. Poly(vinyl chloride) catheters modified with $\mathrm{pH}$-responsive poly(methacrylic acid) with affinity for antimicrobial agents. Radiat. Phys. Chem. 2018, 142, 107-114. [CrossRef]

38. Das, S.S.; Bharadwaj, P.; Bilal, M.; Barani, M.; Rahdar, A.; Taboada, P.; Bungau, S.; Kyzas, G.Z. Stimuli-Responsive Polymeric Nanocarriers for Drug Delivery, Imaging, and Theragnosis. Polymer 2020, 12, 1397. [CrossRef]

39. Bedoya, D.A.; Figueroa, F.N.; Macchione, M.A.; Strumia, M.C. Stimuli-Responsive Polymeric Systems for Smart Drug Delivery; Springer International Publishing: Amman, Jordan, 2020; ISBN 9783030469238.

40. Pasparakis, G.; Tsitsilianis, C. LCST polymers: Thermoresponsive nanostructured assemblies towards bioapplications. Polymer 2020, 211, 123146. [CrossRef]

41. Sponchioni, M.; Palmiero, U.C.; Moscatelli, D. Thermo-responsive polymers: Applications of smart materials in drug delivery and tissue engineering. Mater. Sci. Eng. C 2019, 102, 589-605. [CrossRef]

42. Gandhi, A.; Paul, A.; Sen, S.O.; Sen, K.K. Studies on thermoresponsive polymers: Phase behaviour, drug delivery and biomedical applications. Asian J. Pharm. Sci. 2015, 10, 99-107. [CrossRef]

43. Meléndez-Ortiz, H.I.; Alvarez-Lorenzo, C.; Concheiro, A.; Bucio, E. Grafting of N-vinyl caprolactam and methacrylic acid onto silicone rubber films for drug-eluting products. J. Appl. Polym. Sci. 2015, 132, 1-11. [CrossRef]

44. Pino-Ramos, V.H.; Flores-Rojas, G.G.; Alvarez-Lorenzo, C.; Concheiro, A.; Bucio, E. Graft copolymerization by ionization radiation, characterization, and enzymatic activity of temperature-responsive SR-g-PNVCL loaded with lysozyme. React. Funct. Polym. 2018, 126, 74-82. [CrossRef]

45. Magaña, H.; Palomino, K.; Cornejo-Bravo, J.M.; Díaz-Gómez, L.; Concheiro, A.; Zavala-Lagunes, E.; Alvarez-Lorenzo, C.; Bucio, E. Polymeric prodrug functionalized polypropylene films for sustained release of salicylic acid. Int. J. Pharm. 2016, 511, 579-585. [CrossRef] [PubMed]

46. Magaña, H.; Becerra, C.D.; Serrano-Medina, A.; Palomino, K.; Palomino-Vizcaíno, G.; Olivas-Sarabia, A.; Bucio, E.; Cornejo-Bravo, J.M. Radiation Grafting of a Polymeric Prodrug onto Silicone Rubber for Potential Medical/Surgical Procedures. Polymer 2020, 12, 1297. [CrossRef]

47. Uddin, S. Development of Biopharmaceutical Drug-Device Products; Springer: Glasgow, UK, 2020; Volume 35, ISBN 978-3-030-31414-9.

48. Paradise, J. Regulating Nanomedicine at the Food and Drug Administration. AMA J. Ethic 2019, 21, E347-E355. [CrossRef]

49. Wu, P.; Grainger, D.W. Drug/device combinations for local drug therapies and infection prophylaxis. Biomaterials 2006, 27, 2450-2467. [CrossRef]

50. Quarterman, J.C.; Geary, S.M.; Salem, A.K. Evolution of drug-eluting biomedical implants for sustained drug delivery. Eur. J. Pharm. Biopharm. 2021, 159, 21-35. [CrossRef] [PubMed] 
51. Alvarez-Lorenzo, C.; Garcia-Gonzalez, C.A.; Bucio, E.; Concheiro, A. Stimuli-responsive polymers for antimicrobial therapy: Drug targeting, contact-killing surfaces and competitive release. Expert Opin. Drug Deliv. 2016, 13, 1109-1119. [CrossRef] [PubMed]

52. Licea-Claverie, A.; Rogel-Hernández, E.; Lopez-Sanchez, J.A.; Castillo-Arámbula, L.A.; Cornejo-Bravo, J.M.; Arndt, K.F. A facile synthesis route for carboxyaryl-methacrylates: A way to obtain aromatic polyelectrolytes. Des. Monomers Polym. 2003, 6, 67-80. [CrossRef]

53. Valencia-Mora, R.A.; Zavala-Lagunes, E.; Bucio, E. Grafting of thermo-sensitive N-vinylcaprolactam onto silicone rubber through the direct radiation method. Radiat. Phys. Chem. 2016, 124, 155-158. [CrossRef]

54. Statgraphics Centurion XVIII. Available online: https://statgraphics.net/ (accessed on 30 December 2019).

55. Shit, S.C.; Shah, P.M. A Review on Silicone Rubber. Natl. Acad. Sci. Lett. 2013, 36, 355-365. [CrossRef]

56. Ashfaq, A.; Clochard, M.-C.; Coqueret, X.; Dispenza, C.; Driscoll, M.S.; Ulański, P.; Al-Sheikhly, M. Polymerization Reactions and Modifications of Polymers by Ionizing Radiation. Polymer 2020, 12, 2877. [CrossRef] [PubMed]

57. Menhofer, H.; Zluticky, J.; Heusinger, H. The influence of irradiation temperature and oxygen on crosslink formation and segment mobility in gamma-irradiated polydimethylsiloxanes. Int. J. Radiat. Appl. Instrum. C 1989, 33, 561-566. [CrossRef]

58. Shaik, M.G.; Karuppaiyan, V. Effect of Ageing on the Tracking Characteristics of High-Temperature Vulcanized Silicone Rubber Hybrid Composites for High Voltage Insulation. Materials 2020, 13, 2242. [CrossRef]

59. Kozanoğlu, S.; Özdemir, T.; Usanmaz, A. Polymerization of N-Vinylcaprolactam and Characterization of Poly(NVinylcaprolactam). J. Macromol. Sci. Part A 2011, 48, 467-477. [CrossRef]

60. Sobhi, H.; Matthews, M.E.; Grandy, B.; Masnovi, J.; Riga, A.T. Selecting polymers for medical devices based on thermal analytical methods. J. Therm. Anal. Calorim. 2008, 93, 535-539. [CrossRef]

61. Xiong, Y.; Rowland, S.; Robertson, J.; Day, R. Surface analysis of asymmetrically aged $400 \mathrm{kV}$ silicone rubber composite insulators. IEEE Trans. Dielectr. Electr. Insul. 2008, 15, 763-770. [CrossRef]

62. Qin, G.; Shen, Z.; Yu, Y.; Fan, L.; Cao, H.; Yin, C. Effect of Silicone Rubber of a Waste Composite Insulator on Cement Mortar Properties. Materials 2019, 12, 2796. [CrossRef] [PubMed]

63. Fang, S.; Hu, Y.; Song, L.; Zhan, J.; He, Q. Mechanical properties, fire performance and thermal stability of magnesium hydroxide sulfate hydrate whiskers flame retardant silicone rubber. J. Mater. Sci. 2007, 43, 1057-1062. [CrossRef]

64. Xuguang, L.; Yougong, W.; FuYi, L. Study on improving the tracking and erosion resistance of silicone rubber. In Proceedings of the 6th International Conference on Properties and Applications of Dielectric Materials (Cat. No.00CH36347), Xián, China, 21-26 June 2000; pp. 342-345. [CrossRef]

65. Magaña, H.; Palomino, K.; Cornejo-Bravo, J.M.; Alvarez-Lorenzo, C.; Concheiro, A.; Bucio, E. Radiation-grafting of acrylamide onto silicone rubber films for diclofenac delivery. Radiat. Phys. Chem. 2015, 107, 164-170. [CrossRef]

66. Vázquez-González, B.; Meléndez-Ortiz, H.I.; Díaz-Gómez, L.; Alvarez-Lorenzo, C.; Concheiro, A.; Bucio, E. Silicone Rubber Modified with Methacrylic Acid to Host Antiseptic Drugs. Macromol. Mater. Eng. 2014, 299, 1240-1250. [CrossRef]

67. Syakur, A.; Berahim, H. Hydrophobic Contact Angle and Surface Degradation of Epoxy Resin Compound with Silicon Rubber and Silica. Electr. Electron. Eng. 2012, 2, 284-291. [CrossRef]

68. Ali, M.; Hackam, R. Recovery of Hydrophobicity of HTV Silicone Rubber after Accelerated Aging in Saline Solutions. IEEE Trans. Dielectr. Electr. Insul. 2009, 16, 842-852. [CrossRef]

69. Bennett, A.J. The absorption of globular proteins. Biopolymers 1973, 12, 1671-1676. [CrossRef] [PubMed]

70. Hameed, N.; Guo, Q.; Hanley, T.; Mai, Y.-W. Hydrogen bonding interactions, crystallization, and surface hydrophobicity in nanostructured epoxy/block copolymer blends. J. Polym. Sci. Part B Polym. Phys. 2010, 48, 790-800. [CrossRef]

71. Meeussen, F.; Nies, E.; Berghmans, H.; Verbrugghe, S.; Goethals, E.; Du Prez, F. Phase behaviour of poly(N-vinyl caprolactam) in water. Polymer 2000, 41, 8597-8602. [CrossRef]

72. Ferraz, C.C.; Varca, G.H.; Ruiz, J.-C.; Lopes, P.S.; Mathor, M.B.; Lugao, A.B.; Bucio, E. Radiation-grafting of thermo- and pHresponsive poly(N-vinylcaprolactam-co-acrylic acid) onto silicone rubber and polypropylene films for biomedical purposes. Radiat. Phys. Chem. 2014, 97, 298-303. [CrossRef]

73. Pietsch, C.; Hoogenboom, R.; Schubert, U.S. PMMA based soluble polymeric temperature sensors based on UCST transition and solvatochromic dyes. Polym. Chem. 2010, 1, 1005-1008. [CrossRef]

74. Zhang, Q.; Hoogenboom, R. Polymers with upper critical solution temperature behavior in alcohol/water solvent mixtures. Prog. Polym. Sci. 2015, 48, 122-142. [CrossRef]

75. Marcus, F.; Colaizzi, J.L.; Barry, H. pH Effects on Salicylate Absorption from Hydrophilic Ointment. J. Pharm. Sci. 1970, 59, 1616-1620. [CrossRef]

76. Chandorkar, Y.; Bhagat, R.K.; Madras, G.; Basu, B. Cross-Linked, Biodegradable, Cytocompatible Salicylic Acid Based Polyesters for Localized, Sustained Delivery of Salicylic Acid: An In Vitro Study. Biomacromolecules 2014, 15, 863-875. [CrossRef]

77. Swietach, P.; Vaughan-Jones, R.D.; Harris, A.L.; Hulikova, A. The chemistry, physiology and pathology of pH in cancer. Philos. Trans. R. Soc. B Biol. Sci. 2014, 369, 20130099. [CrossRef] [PubMed]

78. Dujić, T.; Causević, A.; Malenica, M. The Effects of Different Concentrations of Acetylsalicylic Acid on Proliferation and Viability of Lymphocytes in Cell Culture. Bosn. J. Basic Med. Sci. 2008, 8, 210-213. [CrossRef]

79. Ponce, A.M.; Vujaskovic, Z.; Yuan, F.; Needham, D.; Dewhirst, M.W. Hyperthermia mediated liposomal drug delivery. Int. J. Hyperth. 2006, 22, 205-213. [CrossRef] [PubMed] 